Article

\title{
Analysis and forecasting the precipitation and temperature in the Dez catchment area
}

\author{
Alireza Chegnizadeh ${ }^{1}$, Mohammad Javad Bahmani ${ }^{2}$ Hamidreza Rabieifar $^{3 *}$, Hossein Ebrahimi ${ }^{4}$ \\ ${ }^{1}$ PhD Candidate in Engineering and Water Resources Management, Department of Civil Engineering, Islamic \\ Azad University, South Tehran Branch \\ 2 Master of Water Engineering and Hydraulic Structures, Department of Civil Engineering, Islamic Azad \\ University, South Tehran Branch \\ $3^{*}$ Assistant Professor, Department of Civil Engineering, Islamic Azad University, South Tehran Branch \\ 4 Associate Professor, Department of Water Engineering, Islamic Azad University, Ghoods Branch \\ *(h_rabieifar@azad.ac.ir)
}

\begin{abstract}
In this study, we have first studied the trend in meteorological data from the Harmaleh, Vanai and Farsesh stations in the 50-year period in the Dez catchment area. The meteorological data will be then forecasted using SWAT and Mann-Kendall. Forecasting the results in the Mann-Kendall and SWAT model has been done using the code written in MATLAB software and RCP $(4.5,8.5)$ scenarios, respectively. Studying the results of the trend in the data of meteorological stations in this catchment area indicated that these two parametric and non-parametric methods have been used to determine trends in meteorological data. The results of the parametric method are positive in all meteorological parameters. Non-parametric method over a period of 50 years shows the presence of trends in the data. The comparison on the forecasting results at maximum temperature suggested that during summer, we will see an increase in temperature compared to the ground state in all three forecasts. The results of the minimum temperature forecast show a decrease in the minimum increase during the winter and the precipitation forecast indicates that at the end of autumn (Nov) precipitation decreased by $20 \mathrm{~mm}$ in the Mann-Kendall and $4.5 \mathrm{RCP}$ while RCP8.5 suggests the increase in precipitation compared to the ground state. Studying the runoff forecast results using SWOT show that at the end of winter (Feb) and almost all spring (Mar, Apr) a decrease of about $40 \%, 15 \%$ and $14 \%$ will be seen, respectively
\end{abstract}

Keywords: Trends in meteorological data, SWAT, RCP, Mann-Kendall forecast

\section{Introduction}

The most important issue in the field of environmental sciences is the climate change process, especially changes in temperature and precipitation. This phenomenon is increasingly important due to its scientific and practical dimensions (environmental and socio-economic effects), since human systems dependent on climatic elements such as agriculture, industry and the like and also designed on the basis of climate stability and will operate so. Significant changes of the earth's temperature or the global warming has been seen as the most important manifestations of climate change in the current century (IPCC, 2007). Climate means the average weather conditions of a region over a long statistical period. The climate of each region is mainly defined based on meteorological parameters, among which temperature and precipitation are the most applied. The significant difference in longterm climate data is known as climate change. Undoubtedly, the climate change is nowadays one of the major challenges which will be defined on a global scale. There are a number of different statistical methods to analyze and study the climate change in a region, which are mainly classified into two categories: parametric and non-parametric. Non-parametric methods are extensively used compared to the parametric ones [20].The R2 test for parametric statistical conditions and the Mann-Kendall test 
for non-parametric statistical conditions can be regarded as the most common methods in analyzing changes in long-term statistics. The R2 test for parametric statistical conditions and the Mann-Kendall test for non-parametric statistical conditions can be regarded as the most common methods in analyzing changes in long-term statistics[14,15]. Ghosh and Verma have studied temperature changes since 1901 up to now to analyze the trend of temperature changes (Tmax, Tmin and Tmean) for the Gangotri basin in the Himalayas. This study has first paid attention on the relationship between the observed data belonging to the National Institute of Hydrology and the Climate Change Research Unit. For this purpose, we have used an 11-year period (2005 to 2015) and we have studied the results obtained by the standard deviation criteria of the data as well as the results of linear correlation in the time series. Next, we have used two non-parametric methods: the Mann-Kendall and Sen's Slope. We have studied temperature data to analyze the trend. The results show the Tmax, Tmin of a decreasing trend in temperature is present in all seasons except winter. The temperature trend in the data has been increasing in winter, while in Tmean, the temperature trend has been increasing in all seasons except May [16].Ahmadi and Radmanesh have studied the average temperature trend of the northern regions of Iran, which included 18 synoptic stations, on a monthly and annual scale (1961-2010) according to the Mann-Kendall test; the results indicated that that $61 \%$ of the stations have experienced a significant increasing trend annually. Among these stations, Arak station has experienced a significant decreasing trend and the Torbat Heydariyeh and Saqez stations have experienced a significant negative trend on an annual scale. In this study, the results show that the temperature in the northern half of the country has increased by an average of about 1.15 degrees in the last half century[2]. Asfaw have examined the trend changes in temperature and precipitation data in Ethiopia's center. The studied precipitation data are related to global precipitation data as well as the Ethiopian Center for Climate Change. Temperature data are obtained from the Climate Change Research Center, which are related to 1901 to 2014. The data were analyzed using parametric methods like linear regression and correlation coefficient and the non-parametric Mann-Kendall method was used to study the trend in the data. The results indicate that the temperature changes in the average, minimum and maximum are $0.046,0.067$ and $0.026^{\circ} \mathrm{C}$, respectively. The results of the Mann-Kendall method suggested that there is a trend in the average and minimum temperature data while no trend is observed in the maximum temperature data[12]. Worshavian study using daily historical data related to the minimum and maximum and average temperatures over a period of 44 years (1961-2004) at 8 synoptic stations have used low and high percentiles in the number of days less than the percentile and in the number of days more than the higher percentiles in order to extract the limit values of temperature; the results show that Kerman has had an increasing trend in all percentiles except $95 \%$. Most stations have shown a significantly increasing trend in limit values of temperature, especially in the minimum temperature[10]. Talaei and Tabari have examined the maximum and minimum temperature trends in annual, monthly and seasonal data in 19 synoptic stations in arid and semi-arid regions of Iran between 1966 and 2005. The results show that the trend of changes in the maximum and minimum temperatures are in all 19 stations while this trend in the monthly data related to Tmin changes are more observable than the Tmax data. In monthly data, the maximum increase in Tmin and Tmax has been 0.827 to $1.585^{\circ} \mathrm{C}$ in all stations per decade, respectively $[17,18,19]$.Hejazizadeh and Parvin have studied temperature and precipitation changes of Tehran station. The data used in Hejazizadeh and Parvin study are related to the temperature and precipitation parameters during 1951-2005. Mann-Kendall statistical-graphical method was used to analyze the data. According to graphic graphs of temperature and precipitation over 55 years of available statistics, some changed have occurred in the temperature element all of which are shortterm climate and trend changes. The trend has been increasing for the annual months and most of the changes have occurred in the early 2000s which are not significant[5]. Javari has tested the trend of seasonal changes, annual precipitation and temperature nationwide in 24 synoptic stations with 50 years statistics from 1975 to 2014. He has used the Mann-Kendal and linear regression methods to show changes in data trend. The results show a combination of increasing and decreasing trends in climatic parameters of annual precipitation and temperature data in different parts of the country [13]. Naderi In a study, the effect of land-use and climate change on runoff of the Green catchment area has been studied using the SWAT model. In this study, we have used the SWAT model to 
analyze the effect of land-use and climate changes on runoff which given the Nash-Sutcliffe and determination coefficients obtained during the calibration phase that are 0.59 and 0.60 as well as during the validation phase that are 0.66 and 0.67 , respectively, this model has acceptable performance in this catchment area. The results show that the decrease in runoff level during 20242050 because of climate changes (precipitation and temperature) is more than the decrease because of land-use changes compared to the 2000-2010 period [11].In order to simulate the effect of the different scenarios of land-use on the hydrology response in the Pinos basin 1 in Sicily 2, the SWAT model has been used. They have examined the effect of three scenarios, including expansion of the agricultural lands, complete deforestation of the basin and the expansion of residential areas on monthly discharge. The simulation results show the capability of the SWAT model in all three scenarios and it was much more significant, especially in the complete deforestation of the basin [21].Using the SWAT model, the effect of climate and land-use changes on the hydrology of the Bago basin in Myanmar has been studied. The results showed that the effect of climate changes on the flow regime is higher than the land-use changes in the near-future. The combined effects of the land-use and climate change can increase the annual flows up to $68 \%$ in the near-future[22].

Zhang et al have studied the runoff changes in four catchment areas in the Luanhe river basin. For the first time, they have used the Mann-Kendall test to identify the long-term precipitation and runoff trends and founded that runoff has a downward trend. The significance level was 0.05 , while the precipitation level in all sub-catchment areas had no significant trend. Then, the moving t-test and cluster analysis were also used to identify the point of change of runoff series[33].

Anil have studied the land-use and climate impact trends using the Mann-Kendall test and SWAT model in the Madikeri study area located in southern India. They have studied climatic parameters such as precipitation and temperature for analysis and the precipitation trend have been examined using the Mann-Kendall test.Their study results indicated that the Harangi and Madapura stations experienced reduced precipitation in January and June and the rain gauge stations in that area has reported a decrease in precipitation, as well. It has been shown that the temperature trend shows an increase in January, the maximum temperature was recorded for April, May and November while the minimum temperature increase was observed in November and December[34].

Makonen have long-term studied the changes in precipitation and the flow of the Nile River using the Mann-Kendall (MK) test and statistical methods. Their study results using the Mann-Kendall (MK) test suggested that there is a statistically insignificant increase in the amount of annual, monthly and long-term precipitation. The findings of the MK test for daily, monthly, annual, and the seasonal flow is statistically significant[35].

Shepherd have studied the ability of the SWAT model to simulate hydrological conditions and water quality in an agricultural basin in an area of Maryland. They introduced some of the advantages of this model like: being large-scale, distributive and compatible with the Geographic Information System (GIS). In the Yellow River catchment area it is required to carefully examine and measure the runoff die to erosion-sensitive geological formations as well as the construction of the Jarreh Dam. Accurate runoff estimation can possibly decrease or increase the area under cultivation of Ramhormoz irrigation networks that are under implementation. This will have great influence on the rate of agricultural and economic development of the region. In this research, we will first examine the trend in the meteorological data. Next, the $t$ meteorological parameters in 2080 will be forecasted using the Mann-Kendall equation and the code written in MATLAB. The forecast of meteorological parameters in 2080 will also be done using RCP4.5, 8.5 scenarios in the SWAT model. The results of these three forecasts as well as runoff forecast using SWAT model in 2080 in the Dez catchment area will be reviewed and compared[36].

\section{Materials and Methods}

\subsection{Area of Study}


The area of study is the Dez River catchment area located in the heights of the Middle Zagros and in the range of geographical coordinates, ' $10^{\circ} 48$ to ' $18^{\circ} 50^{\circ}$ east longitude and ' $35^{\circ} 31^{\prime}$ to $05^{\circ}$ $34^{\prime}$ north latitude. The area of this basin is about 23,250 square kilometers and includes 4 sub-basins of Tire, Bakhtiari, Sezar and Dez Payeen. Dez plain is part of the Dez river catchment area. This area with the coordinates of $9^{\circ} 48$ to $47^{\circ} 48$ east longitude and $2^{\circ} 32$ to $36^{\circ} 32$ north latitude, which reaches to the Sarab Jeldon basin from the north, Ovan from the west, Mian-Ab of Shooshtar from the southeast, Gotvand-Aghili from the east and Lali from the northeast. This basin is generally located between the five provinces of Isfahan, Markazi, Chaharmahal Bakhtiari, Lorestan and Khuzestan. Most of its area is located in Lorestan and then Khuzestan provinces, respectively. The studied part of this basin is located in the north to the center of Khuzestan province. In order to study the base period and simulate the runoff, the data of three hydrometric stations of the Tele Zang, Bakhtiari and Sezar have been used. The precipitation and temperature data were used by the meteorological stations in the area to study the monthly changes in temperature and precipitation as well as modeling in the Swat model, runoff simulation and comparison and analysis with modeling and forecasting in the future[4]. The specifications of these stations are given in Table (1).

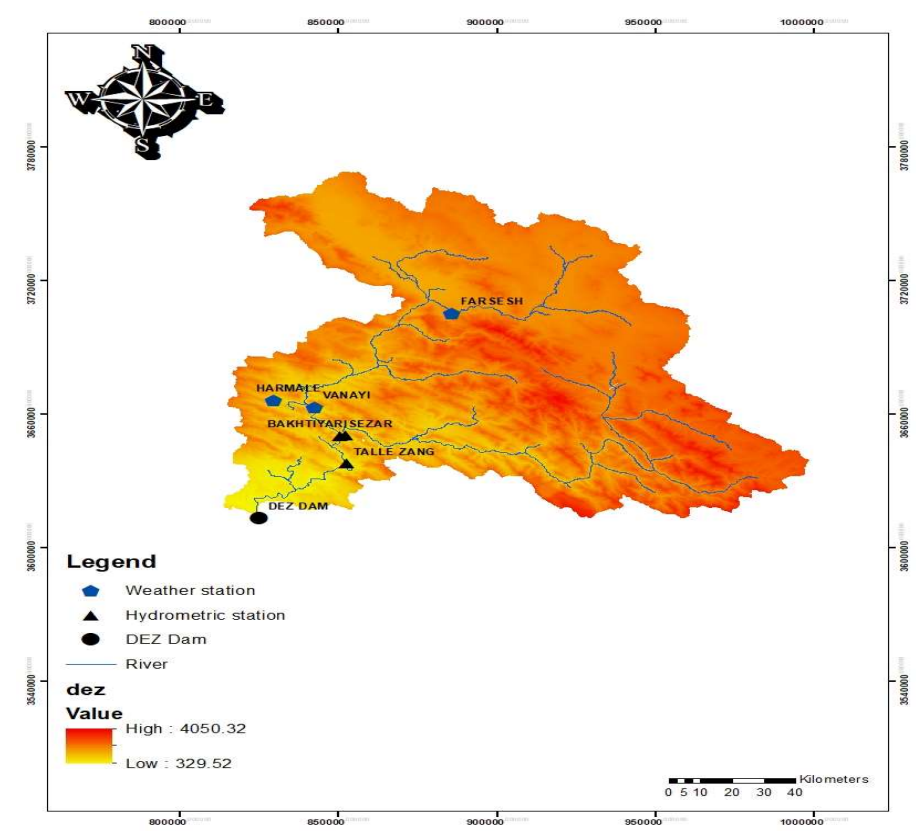

Figure1. Area of Study

Table1. Specifications of Hydrometric Stations

\begin{tabular}{ccccccc}
\hline Height & utmy & utmx & Lat & Long & Station & Station Type \\
\hline 28 & 3538097 & 269244 & $31-35-00$ & $48-52-00$ & Harmale & Rain gauge \\
\hline 2250 & 3753426 & 274965 & $35-53-50$ & $48-33-59$ & Vanayi & Rain gauge \\
\hline 2700 & 3666627 & 392626 & $33-07-59$ & $49-50-56$ & Fersesh & Rain gauge \\
\hline 600 & 3647682 & 289043 & $32-56-00$ & $48-45-00$ & Sezar & Hydrometry \\
\hline 600 & 3646441 & 290774 & $32-56-00$ & $48-46-00$ & Bakhtiyari & Hydrometry \\
\hline
\end{tabular}




\subsection{Examining the trend in data}

We have used the following two methods to study the existence of trends in the data:

\subsubsection{Mann-Kendall Test}

The Mann-Kendall method was first proposed by Mann (1940) and then developed by Kendall (1970). The null hypothesis of the Mann-Kendall test indicates that the trend in the data series is random and the acceptance of the hypothesis 1 (rejection of the null hypothesis) will suggest the existence of a trend in the data series. In this method, the difference between each observation and all subsequent observations is first calculated and obtained according to the following relation:

$$
S=\sum_{k=1}^{n-1} \sum_{j=k+1}^{n} \operatorname{sgn}\left(\mathrm{x}_{j}-\mathrm{x}_{k}\right)
$$

Where $\mathrm{n}$ is the number of series observations, $\mathrm{x}_{j}$ and $\mathrm{x}_{k}$ are the data of $\mathrm{j}^{\text {th }}$ and $\mathrm{k}^{\mathrm{th}}$ of the series, respectively. The sgn symbol function can also be calculated as follows:

$$
\operatorname{sgn}(x)= \begin{cases}+1 & x>0 \\ 0 & x=0 \\ -1 & x<0\end{cases}
$$

The next step is to calculate the variance $S$ by one of the following equations:

$$
\begin{aligned}
& \text { for } n>10 \\
& \operatorname{var}(\mathrm{s})=\frac{n(\mathrm{n}-1)(2 \mathrm{n}+5)-\sum_{i=1}^{m} t(\mathrm{t}-1)(2 \mathrm{t}+5)}{18} \\
& \text { for } n<10 \\
& \operatorname{var}(\mathrm{s})=\frac{n(\mathrm{n}-1)(2 \mathrm{n}+5)}{18}
\end{aligned}
$$

Where $\mathrm{n}$ and $\mathrm{m}$ represent the number of sequences in which there is at least one duplicate data, $\mathrm{t}$ also represents the frequency of data with the same value in a sequence (number of nodes). Finally, the $Z$ statistic is extracted using one of the following equations:

$$
z= \begin{cases}\frac{s-1}{\sqrt{\operatorname{var}(s)}} & s>0 \\ 0 & s=0 \\ \frac{s+1}{\sqrt{\operatorname{var}(s)}} & s<0\end{cases}
$$

Assuming that the trend test is two-tailed, the null hypothesis is accepted if the following condition is met: 


$$
|Z|<Z_{\frac{\alpha}{2}}
$$

where $\alpha$ is the significant level that is considered for the test and $Z_{\alpha}$ is the standard normal distribution statistic at $\alpha$ and $\frac{Z}{2}$ has been used given the test is two-tailed. In the present study, this test has been used at $95 \%$ confidence level $[14,15,6]$

\subsubsection{Regression Test}

The linear regression method is the simplest definition of the process of changing climatic parameters which the function of the dependent and independent variables will be $Y$ (the parameter in question) and $X$ (year number), respectively. We need to determine the best line that can fit the available data to analyze the correlation. Least Squares Method is one of methods of line fitting. In this method, we will fit the line on the points in a manner in which the sum of the squares of the deviations of all points of the line will reach to their minimum. The squares of the errors are defined according to the following equation[1,6]:

$$
\begin{aligned}
& Y_{i}=a+b X_{i} \\
& M D=\sum_{i=1}^{n}\left(Y_{i}-\hat{Y}_{i}\right)^{2} \\
& \hat{Y}_{I}=a+b X
\end{aligned}
$$

We first use a linear coordinate system which the years and the values of data related to those years will be put on its horizontal and vertical axes, respectively. Then a straight line with $y=a x+b$ equation will be crossed between the points. We will say the data will have a trend if the time series data have a uniform ascending or descending course[7].

\subsubsection{Future data of the climate:}

We have used GCM at the desired scale for hydrological modeling of climate change impact studies.

The Atmosphere-Ocean General Circulation Paired-3D Models (AOGCM) are now the most valid tool in order to produce climatic scenarios. This data set can be freely available through the data distribution center formed by the IPCC in 1998 (www.IPCC-data.org). To access data related to the study area in the basic and future 20-year periods, we can enter the spatial coordinates of the desired area as well as the statistical length required for temperature and precipitation time series in the basic and future periods then the monthly output of these variables is obtained in two time periods[9].

The RCPs define as a set of the emission scenarios of $\mathrm{CO}_{2}$ concentration. They measure the radiation from 2.6 to 8.5 watts per square meter compared to 1750 . These scenarios are as follows: RCP2.6, RCP4.5, RCP6 and RCP8.5. RCP 2.6 The goal of these scenarios is to keep the global average temperature below $2^{\circ} \mathrm{C}$.

General Climate Models (GCM) use these RCPs to generate future climate data. 
On a global scale, these scenarios depend on political, social and economic conditions. They are selected given the current global political situation and its possible future path. The RCP 4.5 and RCP6.0 are known as moderate and severe path, respectively. Because the horizontal resolution of GCMs is low, therefore, regional extraction of climate information scales from them is not easy. The GCM results aren't generally reliable for models with a resolution of less than $200 \mathrm{~km}$; however, they are required to be used for important climatic variables such as precipitation and temperature.

The forecasting of the future climate change involves assessing a number of different uncertainties, some of which are related to the climate system among other things the climate is sensitive to increase the concentrations of greenhouse gases in the atmosphere. Other things such as the amount of gases emitted can be forecasted using energy system models to simulate different scenarios. In these scenarios the impact of a wider set of human emissions, including $\mathrm{CO}_{2}, \mathrm{CH}_{4}, \mathrm{~N}_{2} \mathrm{O}$ gases are considered. Chemical active gases such as carbon monoxide (CO) and volatile organic compounds (VOCs) have also been examined. Because RCPs are based on existing scenarios, each indicates a different set of underlying socioeconomic assumptions. RCP4.5 is a stabilizing scenario and so assumes the implementation of emission reduction policies. The RCP4.5 is derived from its "reference" or "no climate policy" scenario. This reference scenario is exclusive to RCP4.5 and is different from RCP8.5 as well as the reference scenarios related to RCP6 and RCP2.6.

The RCP 2.6 made by the IMAGE modeling team, the Dutch Environmental Assessment Agency. The emission path for existing resource scenarios leading to greenhouse gas concentration levels has estimated very little. The RCP2.6 is known as "low emission". In this scenario, the future requires: low energy intensity, $\mathrm{CO}_{2}$ emissions will remain at today's level until 2020, then decrease and become negative in 2100, world population will be 9 billion by 2100, reduction of oil use and methane emissions will decrease by $40 \%$.

The RCP 4.5 was developed by the MiniCAM modeling team in the Global Pacific National Laboratory for Joint Global Change Research Institute (JGCRI). RCP4.5 is known as "Moderate Emission". This future coincides with the followings: reduce the use of crop farms and grasslands due to increased performance and dietary changes, stable methane emissions and $\mathrm{CO}_{2}$ emissions will increase around 2040 just before the decline starts.

This RCP8.5 scenario is compatible with the future and won't make any change in policies to reduce the emissions. RCP8.5 is known as "High Emissions." This future coincides with the followings: rapid increase in methane emissions, high reliance on fossil fuels, high energy intensity, 12 billion people in the world by 2100, and increased use of crops farms and grasslands due to population growth.

\subsubsection{Data forecasting}

Based on the Mann-Kendall model, the values of meteorological parameters can be forecasted. Different methods and formulas have been invented accordingly. we have proposed one of the climate forecasting models as follows:

$$
t_{k}=\mu_{t}+p_{1 t}\left(t_{k-1}-\mu_{t}\right)+\sqrt{1-p_{1, T}^{2}} \sigma_{T} v_{K}
$$

\footnotetext{
$t_{k}$ In this equation, the k-day temperature is obtained from the average temperature of the monthly period and the autocorrelation coefficient with a $p_{1, k}$ delay and standard deviation of data. This is a proper method for when the average data of a monthly period are available and we want to obtain
} 
the daily temperature data with one-day periods. The above-mentioned method can also be used for long-term data with some modifications in such a way that monthly data can be forecasted based on data available over a long period of time. In this case, the forecasted average monthly temperature is as follows[26,27,28].

$u_{T_{i, j}}=S_{T_{J}} \times\left(i-y_{0}\right)+u_{T J}^{\prime} p_{t_{i}}^{\prime} \cdot \frac{\sigma^{\prime} T_{i}}{\sigma^{\prime} T_{j-1}} \cdot\left(u_{i, j-1}-u_{T j}^{\prime}\right)+\sqrt{1-p_{T_{j}}^{\prime 2}} \sigma^{\prime}{ }_{T_{j}} v_{i, j}$

Where,

$u_{T i, j}$ : Forecasted average temperature in month $\mathrm{j}$ in year $\mathrm{i}$.

$S_{T J}$ : Temperature and year regression line slope in month $\mathrm{j}$, which can be calculated based on the available data from the regression equation. (Initial data only)

$y_{0}$

: The number of the year from which the forecasts start

$u_{T j}^{\prime}$ : The average monthly temperature of month $\mathrm{j}$ during the period when the statistics are available

$p_{T_{J}}^{\prime}$ : Regression coefficient between the temperature of month $\mathrm{j}$ and month $\mathrm{j}-1$ in the existing statistical period

$\sigma_{T_{j}}^{\prime}$ : Standard deviation of temperature data in month $\mathrm{j}$

$v_{i, j}$ : Normal random variable (the mean of a series of random numbers is 0 and their standard deviation is 1)

\subsubsection{Introducing the SWAT Model}

The SWAT is a hydrological model developed by the American Agricultural Research Organization. The main hydrological processes which are simulated by the model include evapotranspiration, surface runoff, snowmelt, surface penetration, deep penetration, groundwater flow and subsurface flows[23].

The river flow, in this model, is supplied by three main sources, including surface runoff, subsurface flow and groundwater flow or base flow from non-enclosed groundwater aquifer. The SWAT model has a physical basis and can be used in watersheds that do not have regular statistics. This model is continuous in time and is proper for long-term modeling and is not designed to simulate single flood events[24].

In the SWAT model each basin is divided into several sub-basins and each sub-basin is divided into several units of hydrological reaction. The water in the soil, surface runoff, nutrient cycle, penetration, plant growth and managerial methods are first calculated as an average weight for each hydrological response unit and then for each sub-basin $[25,29]$. The hydrological cycle simulated by the SWAT model based on the water balance equation is as follows: 


$$
S W t=S W 0+\Sigma t(R d a y-Q s u r f-E a-W s e e p-Q g w)
$$

$\mathrm{i}=1$

Where,

$\mathrm{SW}_{\mathrm{t}}$ is the final amount of water in the soil in millimeters;

$\mathrm{SW}_{\mathbf{0}}$ : The initial amount of water in the soil in millimeters (up to a depth of $30 \mathrm{~cm}$ );

t: time in days;

$\mathrm{R}_{\text {day }}$ : The amount of precipitation in day i in millimeters;

Qsurf: The amount of surface runoff in day i in millimeters;

Ea: The amount of actual evapotranspiration in day $\mathrm{i}$ in millimeters;

$\mathrm{W}_{\text {seep: }}$ The amount of water permeation into the top layer of soil (unsaturated area) in day i in millimeters and

$\mathrm{Q}_{\text {gw: }}$ The groundwater flow to the river in day $\mathrm{i}$ in millimeters.

\subsubsection{Hydrologic Response Unit (HRU)}

There are two methods for estimating surface runoff in the Swat model: Curve number method and Green-amp penetration relationship. In this study, we have used the curve number method. An indicator of flood erosion ability is the maximum runoff and it is used to forecast the sediment discharge. SWAT calculates the maximum runoff using a logical (reasoning) method:

$$
q_{\text {peak }}=\frac{C I A}{3.6}
$$

Where,

qpeak: Maximum flood (cubic meters per second);

C: Runoff coefficient;

I: Precipitation intensity $(\mathrm{mm} / \mathrm{h})$;

A: The area of the basin (square kilometers).

In this study, we have used the Hargreaves-Samani method to determine the evapotranspiration. The water flow in the open channel has a free surface. SWAT uses the Manning relation to determine the flow velocity. The Muskingam method was also used to route the flow in the canal.

In order to model the hydrological conditions of the basin using the SWAT model, we have first entered the digital elevation model with a resolution of 50 meters and the waterway network map of the Dez catchment area to the soft environment of the model (ArcSWAT). Then, we have defined the hydrological reaction units (HRU) using the maps of land use, soil and slope classes[30,31,32]. 


\subsubsection{SWAT model calibration results}

Monthly runoff calibration results for the Sezar hydrometric station and the results of other stations are presented in Figure 2 and Table 2, respectively. Calibrated results show good model simulation for the Sezar hydrometric station in the calibration period. In addition, monthly runoff validation results are reported in Table 3. Results of runoff forecast parameters like the calibration period were good and satisfying. The SWAT model in runoff simulation for the area of study has reported good results. The values of the parameters specified separately in Table 2 .

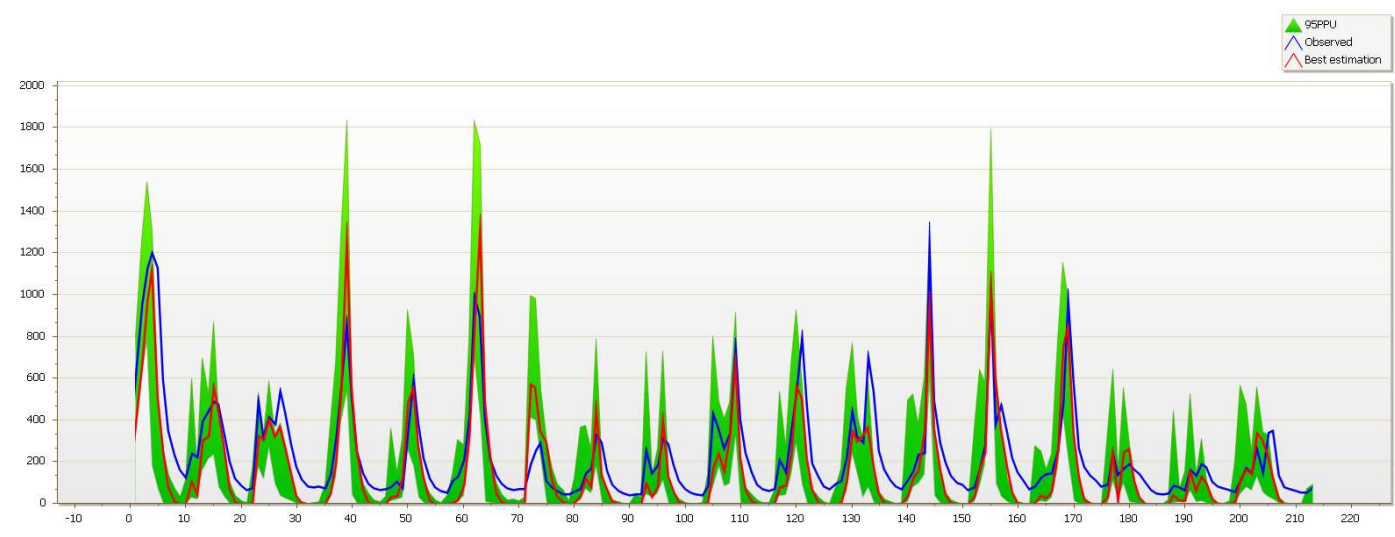

Figure2.

\section{Table2.}




\begin{tabular}{|c|c|c|c|}
\hline Parameter_Name & Fitted_Value & Min_value & Max_value \\
\hline r__CN2.mgt & -0.269400 & -0.35 & 0.35 \\
\hline V_ALPHA_BF.gw & 0.035875 & 0.001 & 0.2 \\
\hline V_GW_DELAY.gw & 41.55000 & 30 & 45 \\
\hline V_GWQMN.gw & 1362.750000 & 10 & 2000 \\
\hline r_LAT_TTIME.hru & -0.272500 & -0.35 & 0.35 \\
\hline r__SURLAG.bsn & -0.017500 & -0.35 & 0.35 \\
\hline r__SLSUBBSN.hru & 0.132500 & -0.35 & 0.35 \\
\hline $\mathrm{v}_{\text {__PLAPS.sub }}$ & -185 & -300 & 300 \\
\hline v__TLAPS.sub & 2.65 & -5 & 5 \\
\hline r__SOL_BD(1).sol & 0.428500 & -0.55 & 0.55 \\
\hline r__SOL_AWC(1).sol & 0.522500 & -0.55 & 0.55 \\
\hline r__SOL_BD(2).sol & -0.35697500 & -0.55 & 0.55 \\
\hline r__SOL_AWC(2).sol & 0.1236500 & -0.55 & 0.55 \\
\hline r__HRU_SLP.hru & -0.247500 & -0.55 & 0.55 \\
\hline v_GW_REVAP.gw & 0.078500 & 0.02 & 0.2 \\
\hline v_REVAPMN.gw & 86.50 & 0 & 100 \\
\hline
\end{tabular}

Table3.

\begin{tabular}{ccccccc}
\hline & \multicolumn{2}{c}{ 1993-2010 } & \multicolumn{4}{c}{ Calibration } \\
\hline Station & Lat & Long & R2 & NS & P-Factor & R-Factor \\
\hline Sezar & $32-56-00$ & $48-45-00$ & 0.65 & 0.52 & 0.55 & 1.17 \\
\hline Bakhtiyari & $32-56-00$ & $48-46-00$ & 0.69 & 0.5 & 0.40 & 0.96 \\
\hline Talezang & $32-49-00$ & $48-46-00$ & 0.79 & 0.67 & 0.49 & 0.98 \\
\hline Station & Lat & Long & R2 & NS & P-Factor & R-Factor \\
\hline Sezar & $32-56-00$ & $48-45-00$ & 0.67 & 0.49 & 0.36 & 0.5 \\
\hline Bakhtiyari & $32-56-00$ & $48-46-00$ & 0.7 & 0.57 & 0.39 & 0.58 \\
\hline Talezang & $32-49-00$ & $48-46-00$ & 0.83 & 0.76 & 0.49 & 0.6 \\
\hline
\end{tabular}




\section{Results and Discussion}

Available data have been evaluated in this section by two methods, Mann-Kendall and SWAT model, respectively. The results of these analyzes can be seen in the following.

\subsection{Examining the trend in the data}

In this study, data related to the statistical period of monthly precipitation, minimum monthly temperature, maximum monthly temperature and average monthly temperature have been first obtained from the Meteorological Agency from 1968 to 2017. The best distribution and the parametric process analysis have been done using SMADA software and R2 method, respectively. Because many trends were not identifiable in the regression result data (due to the very low slope of the line they have), therefore, we have used the mean hypothesis test to identify the trends in the data. So, to use this statistical method, we have tested available data in the important months of the year (for example, warm months of June, July and August for the highest temperatures) based on the conditions of maximum and minimum monthly temperature. For the average temperature in the data of each month, we have randomly selected a month from all seasons of the year.

The data were initially divided into two periods of 20 and 28 years with the assumption of being independent. 20-year and 28-year periods were divided from 1998 to 2017 and from 1970 to 1977, respectively. The results are shown in Tables 1 to 3 entitled (T.B.A.T). We have used the 5\% level in the hypothesis test for means to identify the existence of a significant trend in important months. The results of non-parametric process in the data are obtained using XLSTAT software. In this Software, the results of Mann-Kendall were examined using the hypothesis test. In the final step, temperature forecasting using the Mann-Kendall method for the whole month in a period of 25 years (1993-2017) has been done and to verify the results obtained from three regression factors, MAE and RMSE have been used.

We first analyzed the data of monthly maximum temperature, minimum monthly temperature and precipitation during the 50-year statistical period for the time series studied. Different tests were fitted, the best of which was made at a significance level of $1 \%$ and $5 \%$ for each month using SMADA software. Then the trend in monthly data was calculated using the parametric method, i.e., R2 and finally, the non- parametric Mann-Kendall method is also used and the results of these calculations for each city are given in Tables 1 to 3 . These results indicate that the best distribution for monthly maximum temperature data based on the best fit on the data in the studied stations includes 2Parameter LogNormal, Normal and Pearson. The results of R2 in this data indicate an upward trend and the results of Mann-Kendall analysis show that there is a significant trend in the data for most of the months. The best fit of the data for a minimum monthly temperature includes 2Parameter LogNormal, Normal and Pearson. The results of R2 suggest an upward trend in this data and the results of Mann-Kendall analysis indicate that there is a significant trend in the data in all stations in most months. The best fir on the data for average monthly temperature data includes 2 Parameters LogNormal, Normal and Pearson. The results of R2 suggest the existence of an upward trend in this data and the results of the Mann-Kendall analysis show that only in the Dezful station a significant trend has been observed in the data and the rest of the stations do not have any trend in their data. The results of the model forecasting to determine the desired error rate at the average, minimum and maximum temperatures are presented in Tables 4 to 6 . According to the results in Tables 4 to 6, which are the measurement results in all temperature data, it can be concluded that due to the high R2 as well as the small MAE between the forecasted data and the available data, the model designed for forecasting the data is suitable and good (the results are regarding the degree).

\subsection{Data Forecasting}


The forecasting made by the Mann-Kendall method and SWAT model can be seen below, respectively:

\subsubsection{Mann-Kendall}

We have used one model in two different software conditions for forecasting the meteorological data. The model is designed in Excel and MATLAB. The work process was as follows: available 50-year data related to all temperature parameters in all three synoptic stations have been divided into two parts and each part was used to forecast the other part. Then, by comparing the results obtained from the model with the results in the data using the validation parameters, the accuracy of the designed model is obtained. In order to validate the considered model, two parameters have been used, which have been obtained according to the forecasted results and the available data. These parameters are: R2, MAE (mean absolute error), RMSE (root-mean square deviation). The results of these forecasting are given in the tables.

Based on the results of Tables 6 to 11, the most suitable distributions in the colder months are the Normal and the Pearson type III and 2 Parameters LogNormal and in the warmer months the Normal and the Pearson type III and 2 Parameters LogNormal.

- The primary results in the maximum temperature data at all stations based on the linear regression show that data have trends and this trend is positive and increasing in all months.

- The results of the hypothesis test in this section in the selected months (June, July and August) indicate that there is a significant trend in the data from the Vanai and Farsesh stations in every three months; but, at the Harmaleh station no significant trend was obtained in the hypothesis test and this suggest that a significant difference in the averages of two time periods can be observed at the Vanai and Farsesh stations. 
Table6. Monthly Specifications results of Farsesh

\begin{tabular}{|c|c|c|c|c|c|c|c|c|c|c|c|c|c|c|c|}
\hline \multirow[b]{2}{*}{ Month } & \multicolumn{5}{|c|}{ Ave Temperature } & \multicolumn{5}{|c|}{ Max Temperature } & \multicolumn{5}{|c|}{ Min Temperature } \\
\hline & B.D & $\mathbf{R}^{2}$ & T.B.A.T & $\mathrm{Z}$ & Trend & B.D & $\mathbf{R}^{2}$ & T.B.A.T & $\mathrm{Z}$ & Trend & B.D & $\mathbf{R}^{2}$ & T.B.A.T & $\mathrm{Z}$ & Trend \\
\hline Jan & 1 & 0.0404 & & 0.91 & $*$ & 2 & 0.1434 & & 2.75 & + & 3 & 0.0764 & $*$ & 1.41 & * \\
\hline Feb & 1 & 0.0346 & * & 0.21 & * & 2 & 0.1728 & & 0.83 & $*$ & 3 & 0.1261 & * & 0.83 & * \\
\hline Mar & 1 & 0.0179 & & 0.79 & * & 3 & 0.0758 & & 1.03 & * & 1 & 0.1043 & & 2.08 & + \\
\hline Apr & 2 & 0.02 & & 0.19 & * & 2 & 0.1295 & & 2.75 & + & 1 & 0.635 & & 1.5 & $*$ \\
\hline May & 3 & 0.0214 & + & 0.76 & * & 2 & 0.1855 & & 2.29 & + & 2 & 0.488 & & 3.09 & + \\
\hline Jun & 3 & 0.0023 & & 0.12 & * & 2 & 0.1074 & + & 1.26 & * & 2 & 0.5719 & & 3.09 & + \\
\hline Jul & 3 & 0.0016 & + & 0.07 & $*$ & 2 & 0.903 & + & 1.96 & + & 3 & 0.5673 & & 3.09 & + \\
\hline Aug & 3 & 0.0277 & & 0.51 & $*$ & 2 & 0.2115 & + & 2.41 & + & 3 & 0.5811 & & 3.09 & + \\
\hline Sep & 2 & 0.1407 & * & 0.84 & * & 2 & 0.0681 & & 2.04 & + & 1 & 0.3518 & & 3.09 & + \\
\hline Oct & 1 & 0.0323 & & 0.26 & * & 2 & 0.0753 & & 1.35 & * & 1 & 0.1388 & & 2.37 & + \\
\hline Nov & 1 & 0.0667 & & 0.83 & * & 1 & $1^{*} 10^{\wedge}-4$ & & 0.32 & * & 1 & 0.1036 & & 1.46 & * \\
\hline Dec & 1 & 0.0047 & & 0.31 & * & 3 & 0.0094 & & 0.16 & * & 1 & 0.106 & * & 1.96 & + \\
\hline
\end{tabular}

+: Has a positive significance trend

- : Has a negative significance trend

*: No significant trend was observed 
Table7. Monthly Specifications results of Harmaleh

\begin{tabular}{|c|c|c|c|c|c|c|c|c|c|c|c|c|c|c|c|}
\hline \multicolumn{6}{|c|}{ Ave Temperature } & \multicolumn{5}{|c|}{ Max Temperature } & \multicolumn{5}{|c|}{ Min Temperature } \\
\hline Month & B.D & $\mathbf{R}^{2}$ & T.B.A.T & $\mathrm{Z}$ & Trend & B.D & $\mathbf{R}^{2}$ & T.B.A.T & $\mathrm{Z}$ & Trend & B.D & $\mathbf{R}^{2}$ & T.B.A.T & $\mathrm{Z}$ & Trend \\
\hline Jan & 1 & 0.1181 & & 1.97 & + & 2 & 0.0163 & & 0.75 & $*$ & 3 & 0.0288 & $*$ & 0.45 & $*$ \\
\hline $\mathrm{Feb}$ & 1 & 0.1053 & + & 2.08 & + & 1 & 0.0051 & & 0.83 & $*$ & 3 & 0.0106 & * & 0.23 & * \\
\hline Mar & 3 & 0.034 & & 0.22 & * & 3 & 0.0284 & & 0.42 & $*$ & 1 & 0.0016 & & 0.44 & $*$ \\
\hline Apr & 3 & 0.0887 & & 2 & + & 2 & 0.0093 & & 1.17 & $*$ & 1 & $8 \mathrm{E}-05$ & & 0.23 & $*$ \\
\hline May & 3 & 0.176 & * & 3.08 & + & 2 & 0.2198 & & 2.75 & + & 2 & 0.0092 & & 0.92 & * \\
\hline Jun & 3 & 0.3564 & & 3.08 & + & 2 & 0.0048 & * & 0.36 & $*$ & 2 & 0.2396 & & 3.09 & + \\
\hline Jul & 3 & 0.4386 & + & 3.08 & + & 2 & 0.0449 & $*$ & 1.1 & $*$ & 3 & 0.273 & & 3.09 & + \\
\hline Aug & 3 & 0.3899 & & 3.08 & + & 2 & 0.075 & $*$ & 1.41 & $*$ & 3 & 0.2971 & & 3.09 & + \\
\hline Sep & 2 & 0.1227 & + & 2.03 & + & 2 & 0.0026 & & 0.16 & $*$ & 1 & 0.136 & & 2.75 & + \\
\hline Oct & 1 & 0.1712 & & 3.08 & + & 2 & 0.0006 & & 0.25 & $*$ & 2 & 0.0635 & & 1.53 & $*$ \\
\hline Nov & 1 & 0.0648 & & 2.23 & + & 1 & 0.0027 & & 0.52 & $*$ & 2 & 0.0018 & & 0.3 & * \\
\hline Dec & 1 & 0.0372 & & 1.22 & $*$ & 3 & 0.016 & & 0.95 & * & 1 & 0.0061 & $*$ & 0.19 & $*$ \\
\hline
\end{tabular}


Table8. Monthly Specifications results of Vanai

\begin{tabular}{|c|c|c|c|c|c|c|c|c|c|c|c|c|c|c|c|}
\hline \multirow[b]{2}{*}{ Month } & \multicolumn{5}{|c|}{ Ave Temperature } & \multicolumn{5}{|c|}{ Max Temperature } & \multicolumn{5}{|c|}{ Min Temperature } \\
\hline & B.D & $\mathrm{R} 2$ & T.B.A.T & $\mathrm{Z}$ & Trend & B.D & R2 & T.B.A.T & $\mathrm{Z}$ & Trend & B.D & R2 & T.B.A.T & $\mathrm{Z}$ & Trend \\
\hline Jan & 1 & 0.0481 & & 1.07 & * & 2 & 0.0263 & & 0.18 & * & 3 & 0.0373 & $*$ & 1.03 & $*$ \\
\hline $\mathrm{Feb}$ & 1 & 0.0873 & $*$ & 0.87 & * & 1 & 0.0356 & & 0.35 & $*$ & 3 & 0.0965 & + & 1.19 & $*$ \\
\hline Mar & 2 & 0.124 & & 1.2 & * & 3 & 0.0778 & & 0.36 & $*$ & 1 & 0.113 & & 1.09 & $*$ \\
\hline Apr & 2 & 0.252 & & 1.3 & * & 2 & 0.1912 & & 0.97 & $*$ & 1 & 7.74E-02 & & 0.47 & $*$ \\
\hline May & 3 & 0.3103 & + & 1.48 & $*$ & 2 & 0.3089 & & 2.27 & + & 2 & 0.3861 & & 2.08 & + \\
\hline Jun & 3 & 0.4135 & & 1.63 & * & 2 & 0.2288 & + & 2.09 & + & 2 & 0.2078 & & 1.49 & $*$ \\
\hline Jul & 2 & 0.304 & + & 0.86 & $*$ & 2 & 0.3862 & + & 1.99 & + & 3 & 0.3647 & & 2.17 & + \\
\hline Aug & 3 & 0.3584 & & 1 & ${ }^{*}$ & 2 & 0.3374 & + & 2.2 & + & 3 & 0.4413 & & 1.35 & $*$ \\
\hline Sep & 2 & 0.1525 & + & 0.48 & $*$ & 2 & 0.2523 & & 1.64 & $*$ & 1 & 0.1056 & & 1.43 & * \\
\hline Oct & 1 & 0.1712 & & 1.21 & $*$ & 2 & 0.1782 & & 1.22 & $*$ & 1 & 0.157 & & 1.46 & $*$ \\
\hline Nov & 1 & 0.0015 & & 0.71 & $*$ & 1 & 0.0042 & & 0.3 & $*$ & 1 & 0.0025 & & 0.3 & $*$ \\
\hline Dec & 1 & 0.0081 & & 0.19 & * & 3 & 0.0189 & & 0.2 & * & 1 & 0.0453 & * & 0.49 & * \\
\hline
\end{tabular}

1: Normal Distribution

2: 2 Parameter Log Normal Distribution

3: Pearson Distribution 
Table9. Validation results in the Mann-Kendall model of the Vanai Station

\begin{tabular}{ccccccccccc}
\hline & \multicolumn{3}{c}{ Precipitation } & \multicolumn{3}{c}{ Max Temperature } & \multicolumn{2}{c}{ Min Temperature } \\
\hline Month & $\mathbf{R}^{2}$ & MAE & RMSE & $\mathbf{R}^{2}$ & MAE & RMSE & $\mathbf{R}^{2}$ & MAE & RMSE \\
\hline Jan & 0.83 & 0.55 & 0.68 & 0.71 & 0.76 & 0.87 & 0.89 & 0.62 & 0.78 \\
\hline Feb & 0.75 & 0.63 & 0.73 & 0.86 & 0.62 & 0.79 & 0.94 & 0.55 & 0.65 \\
\hline Mar & 0.94 & 0.72 & 0.8 & 0.94 & 0.61 & 0.74 & 0.86 & 0.72 & 0.84 \\
\hline Apr & 0.84 & 0.61 & 0.7 & 0.83 & 0.63 & 0.73 & 0.92 & 0.75 & 0.81 \\
\hline May & 0.82 & 0.8 & 0.9 & 0.82 & 0.5 & 0.65 & 0.85 & 0.5 & 0.6 \\
\hline Jun & 0.72 & 0.72 & 0.88 & 0.73 & 0.66 & 0.79 & 0.83 & 0.63 & 0.75 \\
\hline Jul & 0.81 & 0.72 & 0.78 & 0.78 & 0.61 & 0.73 & 0.77 & 0.58 & 0.66 \\
\hline Aug & 0.72 & 0.53 & 0.62 & 0.72 & 0.44 & 0.51 & 0.76 & 0.7 & 0.83 \\
\hline Sep & 0.72 & 0.61 & 0.69 & 0.85 & 0.47 & 0.59 & 0.86 & 0.62 & 0.76 \\
\hline Oct & 0.72 & 0.68 & 0.75 & 0.88 & 0.53 & 0.65 & 0.87 & 0.68 & 0.78 \\
\hline Nov & 0.74 & 0.44 & 0.57 & 0.92 & 0.53 & 0.65 & 0.93 & 0.55 & 0.68 \\
\hline Dec & 0.76 & 0.77 & 0.83 & 0.85 & 0.67 & 0.87 & 0.95 & 0.38 & 0.48 \\
\hline
\end{tabular}

Table10. Validation results in the Mann-Kendall model of the Farsesh Station

\begin{tabular}{cccccccccc}
\hline & \multicolumn{3}{c}{ Precipitation } & \multicolumn{2}{c}{ Max Temperature } & \multicolumn{2}{c}{ Min Temperature } \\
\hline Month & $\mathbf{R}^{2}$ & MAE & RMSE & $\mathbf{R}^{2}$ & MAE & RMSE & $\mathbf{R}^{2}$ & MAE & RMSE \\
\hline Jan & 0.96 & 0.50 & 0.56 & 0.85 & 0.80 & 0.93 & 0.83 & 0.79 & 0.94 \\
\hline Feb & 0.81 & 0.64 & 0.78 & 0.89 & 0.84 & 0.92 & 0.71 & 0.82 & 0.91 \\
\hline Mar & 0.84 & 0.77 & 0.9 & 0.84 & 0.82 & 0.95 & 0.76 & 0.84 & 0.93 \\
\hline Apr & 0.81 & 0.77 & 0.93 & 0.81 & 0.86 & 0.96 & 0.94 & 0.83 & 0.96 \\
\hline May & 0.76 & 0.88 & 0.95 & 0.70 & 0.84 & 0.96 & 0.71 & 0.77 & 0.86 \\
\hline Jun & 0.82 & 0.74 & 0.87 & 0.82 & 0.84 & 0.93 & 0.70 & 0.77 & 0.94 \\
\hline Jul & 0.71 & 0.72 & 0.86 & 0.70 & 0.84 & 0.82 & 0.76 & 0.84 & 0.92 \\
\hline Aug & 0.73 & 0.83 & 0.95 & 0.71 & 0.73 & 0.86 & 0.78 & 0.76 & 0.84 \\
\hline Sep & 0.70 & 0.72 & 0.87 & 0.71 & 0.80 & 0.92 & 0.72 & 0.88 & 0.96 \\
\hline Oct & 0.75 & 0.89 & 0.96 & 0.83 & 0.83 & 0.95 & 0.85 & 0.77 & 0.89 \\
\hline Nov & 0.71 & 0.88 & 0.98 & 0.80 & 0.83 & 0.96 & 0.95 & 0.57 & 0.7 \\
\hline Dec & 0.82 & 0.89 & 0.98 & 0.84 & 0.78 & 0.86 & 0.77 & 0.83 & 0.95 \\
\hline
\end{tabular}

Table11. Validation results in the Mann-Kendall model of the Harmaleh Station 


\begin{tabular}{cccccccccc}
\hline & \multicolumn{3}{c}{ Precipitation } & \multicolumn{3}{c}{ Max Temperature } & \multicolumn{3}{c}{ Min Temperature } \\
\hline Month & $\mathbf{R}^{2}$ & MAE & RMSE & $\mathbf{R}^{2}$ & MAE & RMSE & $\mathbf{R}^{2}{ }^{\prime \prime}$ & MAE & RMSE \\
\hline Jan & 0.78 & 0.69 & 0.8 & 0.91 & 0.81 & 0.98 & 0.9 & 0.69 & 0.86 \\
\hline Feb & 0.81 & 0.76 & 0.9 & 0.72 & 0.68 & 0.81 & 0.81 & 0.82 & 0.92 \\
\hline Mar & 0.77 & 0.78 & 0.9 & 0.91 & 0.87 & 0.97 & 0.75 & 0.78 & 0.94 \\
\hline Apr & 0.71 & 0.86 & 0.96 & 0.82 & 0.87 & 0.95 & 0.83 & 0.77 & 0.9 \\
\hline May & 0.87 & 0.83 & 0.97 & 0.89 & 0.85 & 0.94 & 0.88 & 0.8 & 0.94 \\
\hline Jun & 0.77 & 0.89 & 0.95 & 0.74 & 0.67 & 0.77 & 0.83 & 0.84 & 0.95 \\
\hline Jul & 0.84 & 0.75 & 0.94 & 0.71 & 0.8 & 0.88 & 0.88 & 0.85 & 0.96 \\
\hline Aug & 0.71 & 0.82 & 0.94 & 0.71 & 0.61 & 0.69 & 0.72 & 0.69 & 0.88 \\
\hline Sep & 0.71 & 0.65 & 0.78 & 0.72 & 0.55 & 0.66 & 0.71 & 0.72 & 0.86 \\
\hline Oct & 0.77 & 0.74 & 0.83 & 0.81 & 0.7 & 0.8 & 0.89 & 0.78 & 0.93 \\
\hline Nov & 0.71 & 0.64 & 0.73 & 0.7 & 0.77 & 0.87 & 0.94 & 0.76 & 0.94 \\
\hline Dec & 0.78 & 0.87 & 0.95 & 0.91 & 0.72 & 0.91 & 0.87 & 0.78 & 0.9 \\
\hline
\end{tabular}

-The results of the Mann-Kendall method at the Farsesh station show the presence of a trend in the data for March, June, September, October and December. At the Vanai station, there are significant trends in the data only in May and a significant trend in the data has been calculated at the Farsesh station in May, June, July and August.

- The results of the Mann-Kendall method at the Harmaleh station indicate that there is no trend in the data. However, there is a significant trend in all months at the Farsesh and Vanai stations except March and December.

- The results of the hypothesis test at the Harmaleh station in the selected months (January, February and December) indicate that there is no trend in the data of these three months, while at the Farsesh station in February this trend is observed.

- The results of the Mann-Kendall method at the Farsesh and Vanai stations show that there is a trend in the data of all months except January, February, April and November. However, a significant trend in data can be observed at the Harmaleh station only in May and at the Vanai station in May, June, July and August.

- The primary results in the minimum temperature data of all stations indicate the existence of a trend, and this trend is positive and increasing in the data of all months.

- The primary results obtained from all stations using the R2 method of average temperature data indicate the existence of a trend, and this trend is positive and increasing in the data of all months.

- The selected months of the Farsesh station (February, May, July and September) indicate that the trend exists only in the data of May and July. However, a trend can be observed at the Harmala station in February, July and September and at the Vanai station in May, July and September.

The results of the hypothesis test at the Harmaleh station in the selected months (January, February and December) indicate that there is no trend in the data of these three months, while at the Farsesh station in February this trend is observed. 
- The results of the Mann-Kendall method at the Farsesh and Vanai stations show that there is a trend in the data of all months except January, February, April and November. However, a significant trend in data can be observed at the Harmaleh station only in May and at the Vanai station in May, June, July and August.

- The primary results in the minimum temperature data of all stations indicate the existence of a trend, and this trend is positive and increasing in the data of all months.

- The primary results obtained from all stations using the R2 method of average temperature data indicate the existence of a trend, and this trend is positive and increasing in the data of all months.

- The selected months of the Farsesh station (February, May, July and September) indicate that the trend exists only in the data of May and July. However, a trend can be observed at the Harmala station in February, July and September and at the Vanai station in May, July and September.

\subsubsection{SWAT Results}

3.2.2.1. Comparison of temperature and precipitation forecast results in The Mann-Kendall, RCP 8.5 and RCP4.5

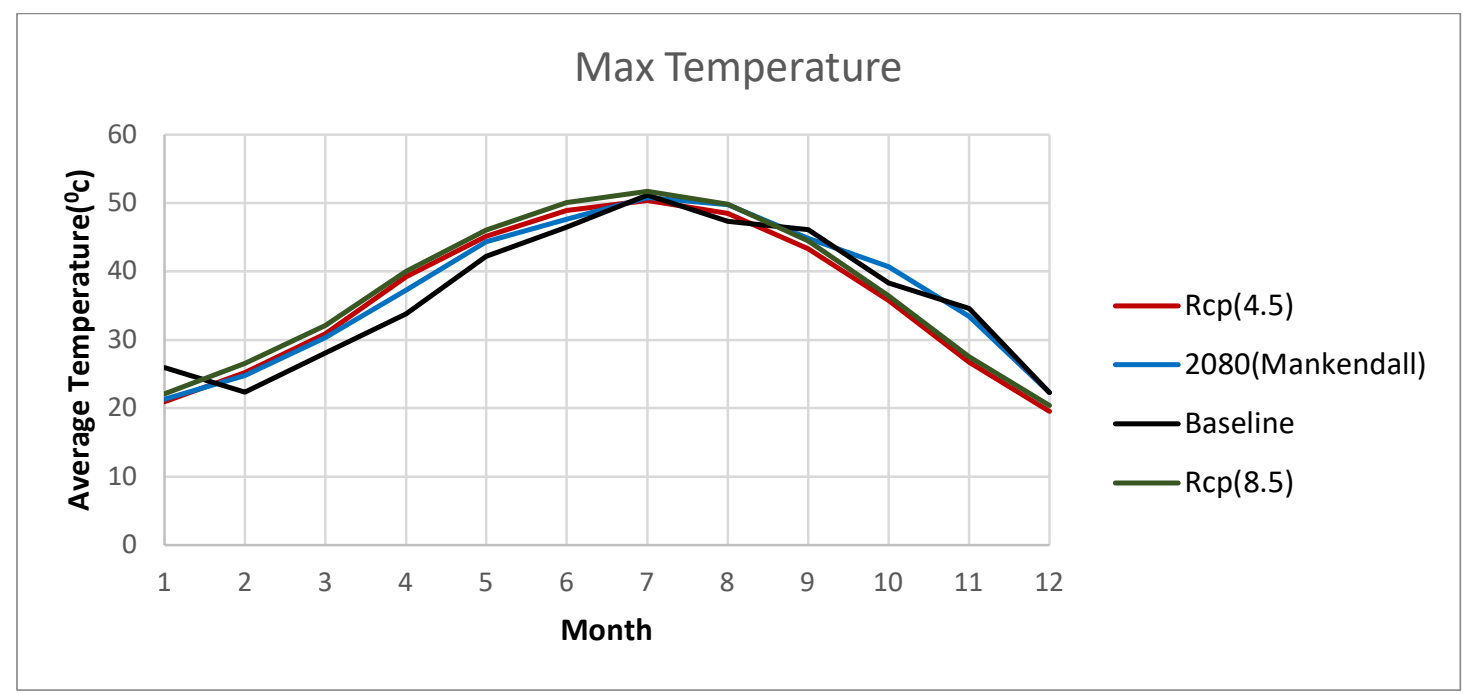

Figure3. Max Temperature

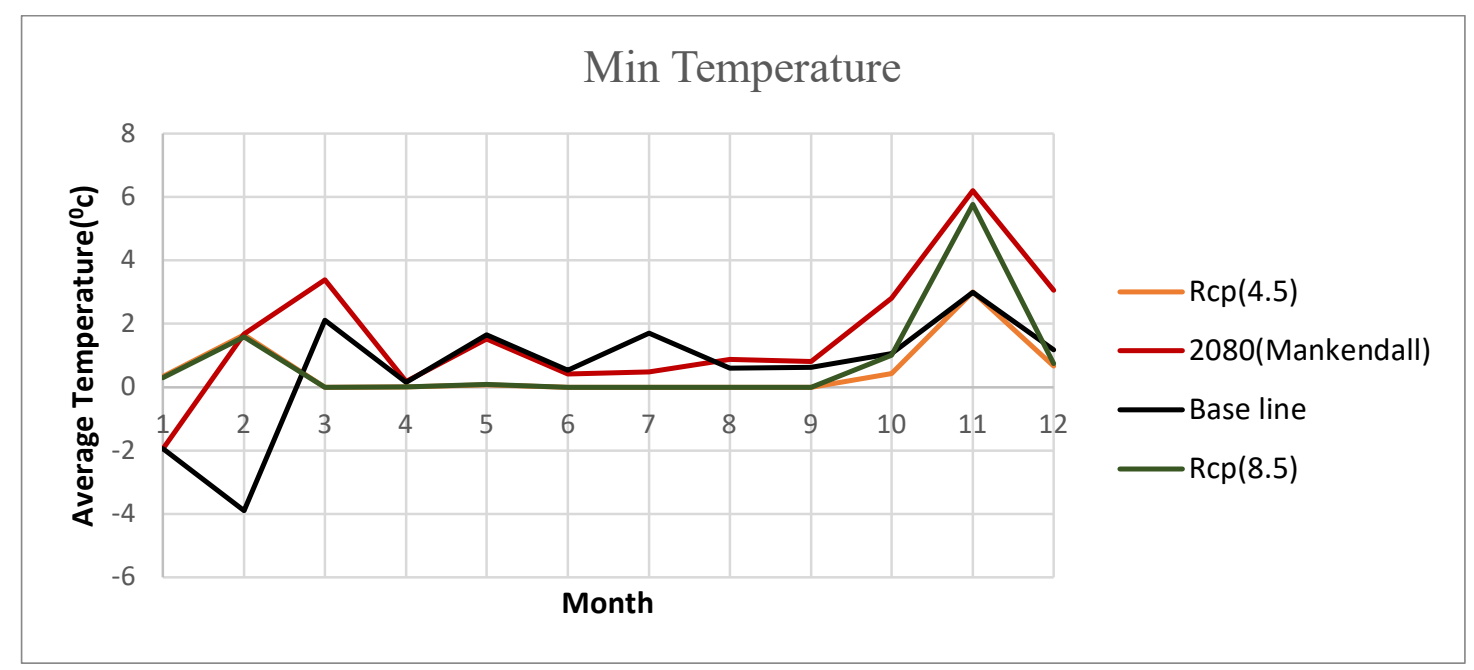

Figure4.Min Temperature 
The maximum and minimum of temperature have very important effects on the hydrological flows. Figures 3 and 4 compare the results in all three different forecasting in 2080 with the basic data. As shown in Figure 3, the forecasting results in winter in the 12th and 1st months (DJ) at the maximum temperature is $1.4^{\circ} \mathrm{C}$ by lowering the maximum temperature in RCP (4.5) and RCP (8.5) according to the basic temperature, while these amounts of changes are not shown in the Mann-Kendall method. While in month 2 (F) in all three cases the temperature increase is $2.6^{\circ} \mathrm{C}$. In three months of spring (MAM) these changes are incremental in all three forecasts and this amount of changes in all three forecasts are in average $3^{\circ} \mathrm{C}$ in all three. The amount of changes in the summer in June shows an increase of almost 2 degrees in all forecasts, while this amount of changes in July is about $0.2^{\circ} \mathrm{C}$. In August, a maximum increase of $1.3^{\circ} \mathrm{C}$ can be observed again compared to the ground state. Autumn results (SON) show that the maximum temperature in the RCP forecasts decreases significantly compared to the ground state. This decrease reached at its maximum in November $\left(5^{\circ}\right.$ C). While the Mann-Kendall method shows an increase in temperature in October, but it is almost unchanged in November.

According to the Figure 4, the minimum temperature for the winter in December is expected to increase based on the Mann-Kendall and 8.5 RCP, while 4.5 RCP estimates this amount of change to be constant relative to the base. In the RCPs, these changes are forecasted to be increased in January and it is estimated to be constant in the Mann-Kendall and equal to ground state. In February, the changes in forecasting of values in all three modes are incremental and significant so that, this amount of changes up to about $5^{\circ} \mathrm{C}$ has also been shown. During the spring (MAM) in March, the amount of changes in RCPs shows an increase in the minimum temperature, while these changes in the MannKendall are estimated to be decreased about $1^{\circ} \mathrm{C}$. An April, all the cases are estimated constant and equal relative to the ground state. In May, changes in RCPs show a decrease in temperature of at least $1.5^{\circ} \mathrm{C}$, while the Mann-Kendall shows no change and the forecast results are equal to the ground state. In summer, the amount of change in the RCPs and Mann-Kendall in June are suggested equal and all three show a decrease in the minimum temperature compared to the ground state. In August, the amount of changes in RCPs shows a decrease in the minimum temperature, while in the MannKendall it is estimated at about $1^{\circ} \mathrm{C}$ increase. The most changes are in November in the autumn so that, the Mann-Kendall shows the amount of changes in the minimum temperature about an increase of $3^{\circ} \mathrm{C}$ compared to the ground state and 8.5 RCP shows these minimum temperature changes of about $2.8^{\circ} \mathrm{C}$ compared to the ground state.

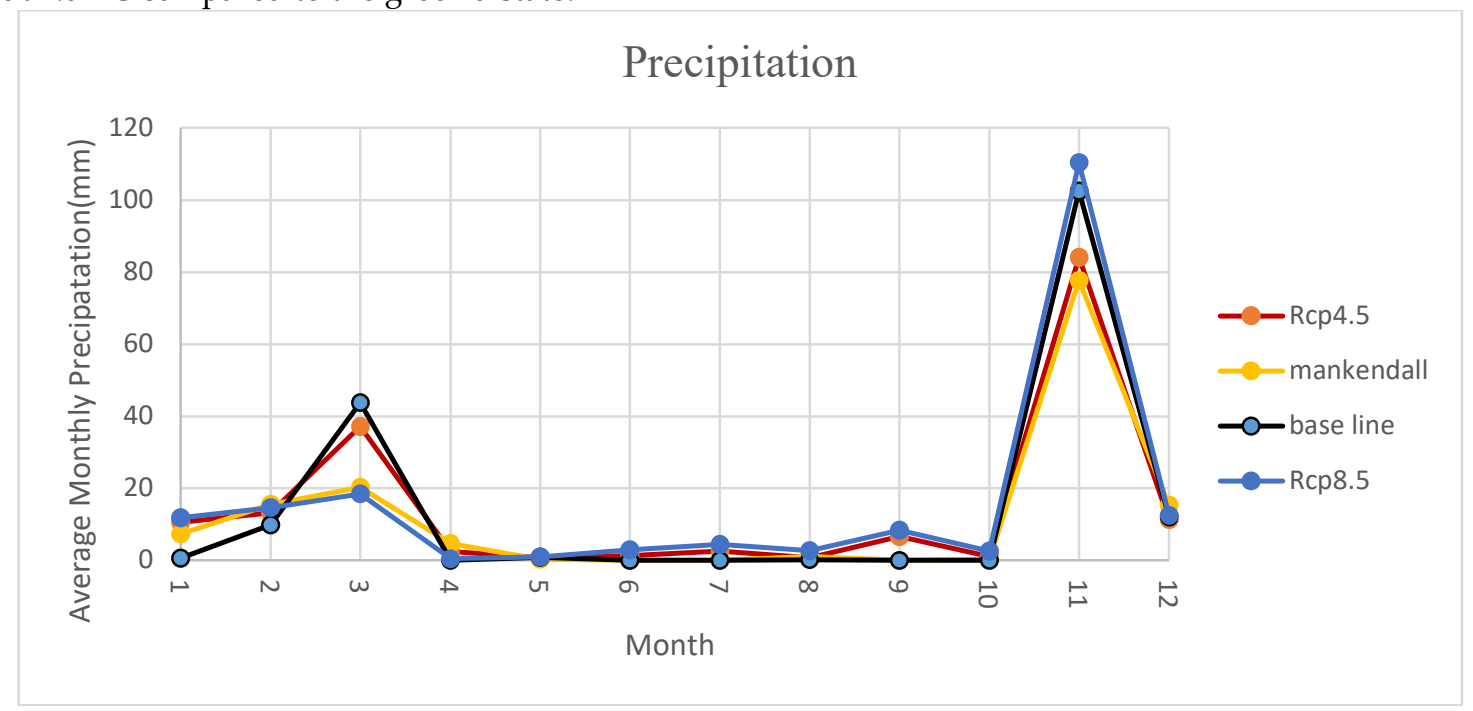

Figure5.Percipitation

According to the Figure 5, the most changes are related to January in the winter so that, the Mann-Kendall and both RCPs show the amount of change about $10 \mathrm{~mm}$ compared to the ground state. In spring, the most changes are related to March so that, the Mann-Kendall and 8.5 RCP show a decrease of about $20 \mathrm{~mm}$ in precipitation, however, $4.5 \mathrm{RCP}$ does not show any significant changes 
compared to the ground state and the changes in this mode are almost zero. In other months, the amount of precipitation is almost constant and we have no changes compared to the ground state. Most changes can be seen in the autumn compared to the ground state so that, Mann-Kendall and 4.5 RCP show a decrease of about $20 \mathrm{~mm}$ in November, but RCP 8.5 forecasts a minimal increase in precipitation during this period.

\subsection{Monthly precipitation changes based on SWAT forecast scenarios:}

According to Figure 6, at the sezar station, which is the most important station of this basin and this research, the runoff changes will decrease by 2080 under both scenarios, with the largest decrease occurring in the RCP8.5 scenario and the lowest decrease in the RCP2.6 scenario. So that, the highest amount of runoff based on basic data is in March, in RCP 8.5, we will have a reduction in runoff of approximately 250 cubic meters per second.

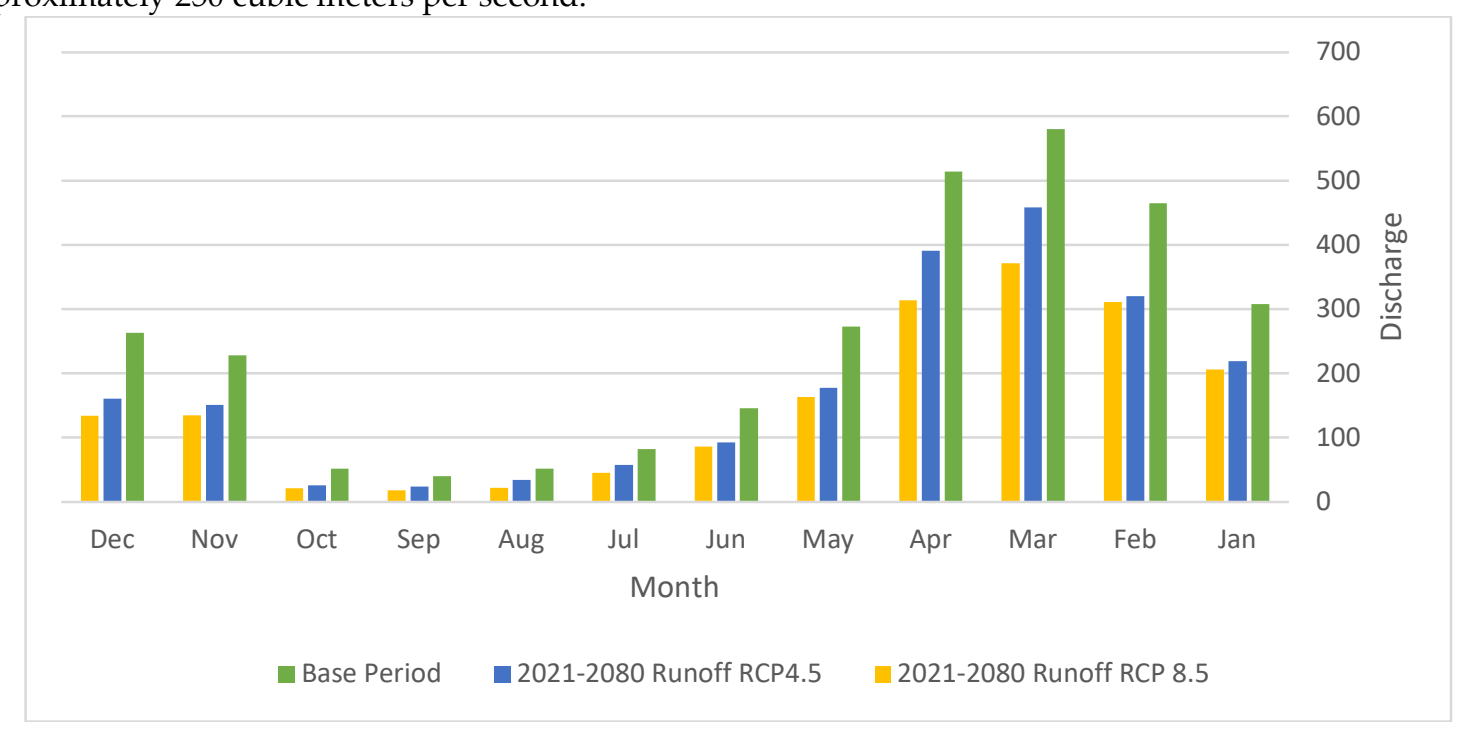

\section{Figure6.Runoff}

\subsection{Formatting of Mathematical Components}

This is an example of an equation:

$$
\mathrm{a}=1,
$$

the text following an equation need not be a new paragraph. Please punctuate equations as regular text.

\section{Conclusions}

In this study, we have evaluated and compared the results of precipitation and temperature parameters in the SWAT and Mann-Kendall models. We first investigated the existence of trends in data using linear and nonlinear statistical methods. Then, the data were forecasted using two different methods of the Mann-Kendall and SWAT semi-distributed model. The results in the MannKendall were obtained using the code written in the MATLAB program and they were used in the SWAT model to forecast the series of GCMs in CMIP5 under two different RCP scenarios (4.5 and 8.5). Calibration was performed in both the Mann-Kendall and SWAT to ensure that the model was based on the ground state results. Due to the results obtained for each of the meteorological stations based on the best distribution, linear regression, the mean hypothesis test and Mann-Kendall, it can be concluded that the changes in the minimum and maximum temperature trends can be observed. In addition, the average temperature increase was observed at the Vanai station, which indicates the upward trend of increasing all temperature parameters in the study area. 
Comparison of the forecasting results in all three cases indicates that the Mann-Kendall and both RCP scenarios at the maximum temperature and precipitation have relatively similar results. At the maximum temperature, all three modes show that in the summer period (6, 7 and 8$)$ in 2080 will have an increase in the maximum temperature compared to the ground state. Precipitation forecasting in the results showed that in January and February, in all three cases a precipitation increase can be observed and in March there is a precipitation decrease. The highest precipitation decrease was forecasted in November. A minimum temperature increase can be seen in winter (December, January and February). The results of the output runoff in ... show that in both RCP scenarios the amount of output runoff will decrease in all months. According to the forecast scenarios, the highest decrease will occur in the late winter and spring. This study can be an example to help to forecast the precipitation and temperature in different ways. In addition, this study can show how future results in different forecasting methods can affect the hydrological cycle of southwestern Iran. The results of this study can help to manage downstream water resources in the Dez catchment area.

\section{References}

1. Ebrahimi, H. Alizadeh, A. Javanmard, S. (2005) Investigating the existence of temperature change in Mashhad plain as an indicator of climate change. Journal of Geographical Research Quarterly, 79, 5-18.

2. Ahmadi, F., Radmanesh, F. (2014). Investigating the trend of average monthly and annual temperature changes in the northern half of the country in the last half century. Journal of Water and Soil (Agricultural Sciences and Industries), 28 (4), 855-865.

3. Ebrahimi, H. (2005). Investigating the changes in trend and forecasting the potential evapotranspiration in Mashhad plain. Journal of Agricultural Sciences, Islamic Azad University, Science and Research Branch.

4. Jahanbakhsh, S., Bandarabadi, S. R., Hosseini, A., Rezaei, S., Zaman, T. Kh (2010). Investigating the precipitation and temperature changes in Karkheh basin. Fourth International Congress of Geographers of the Islamic World. Zahedan.

5. Zadeh, Z. (2009). Study of temperature and precipitation changes in Tehran during the last half century. Geography and Regional Planning, 43-56.

6. Tavousi, T., Rakhshani, Z., Firoozi, F. (2014). Analysis of the trend of maximum and minimum seasonal and annual temperature changes in Fars province using non-parametric methods. Nivar, 86, 30-40.

7. Alizadeh, D., A. (2014). Principles of Applied Hydrology. Mashhad: Imam Reza University Press.

8. Marianji, Z., Javid, K., Al-Muluki, Sh. (2016). Examining the temperature time series in order to identify changes in its trend in Isfahan province using Mann-Kendall method, Sepehr, 22-86.

9. Mozaffari, Gh., Shafiee, Sh. (2016). Study and analyze the annual precipitation 1 trends in western regions of Iran. Journal of Applied Research in Water Sciences, 1 (2), 49-58.

10. Worshavian, W., Khalili, A., Ghahraman, N., Hojam, S. (2011). Evaluating the trend of changes in the minimum, maximum and daily average temperature limits in Iranian climatic samples. Journal of Earth and Space Physics, 1 (37), 169-179.

11. Naderi, M., Nouri, H., Eildarmi, A., Zeini Vand, H., Agha Beigi, Amin, S., (2015). Evaluating the effect of land use and climate change on the runoff of the catchment area using SWAT model (Case Study: Green Catchment Area). Master Thesis, Malayer Universit

12. Asfaw, A., Simane, B., Hassen, A., \& Bantider, A. (2017). Variability and time series trend analysis of rainfall and temperature in northcentral Ethiopia: A case study in Woleka sub-basin. Weather and Climate Extremes, 1-13.

13. Javari, M. (2016). Trend and Homogeneity Analysis of Precipitation. climate, 4(44), 1-23.

14. Kendall, M. (1970). Rank Correlation Methods. New York: Hafner.

15. Mann, H. (1945). Nonparametric tests against trend. Econometrica, 13, 245-259.

16. Prateek Verma, S. K. (2019). Trend Analysis of Climatic Research Unit Temperature. Dynamics of Atmospheres and Oceans.

17. Tabari, H., \& Talaee, P. H. (2011). Global and Planetary Change, 79, 1-10.

18. Tabari, H., Somee, B. S., \& Zadeh, M. R. (2011). Atmospheric Research, 100, 132-140.

19. Tabaria, H., Marofia, S., Aeinia, A., Talaeea, P. H., \& Mohammadib, K. (2011). Trend analysis of reference evapotranspiration in the western half of Iran. Agricultural and Forest Meteorology, 151, 128-136. 
20. Xu, z., Tkechi, k., \& Ishidaria, h. (2003). Monotonic trend and step changes in japanese precipitation. Hydrology, 144-150.

21. Pikounis, M., Aranou, E., Baltas, E., Dassaklis, A., and Mimikou, M. 2003. Application of the SWAT model in the Pinos River in under different land-use Scenarios, Global Nest J., 5: 2. 71-79.

22. Shrestha, S., A.Y. Htut. 2016. Land Use and Climate Change Impacts on the Hydrology of the Bago River Basin, Myanmar. Environmental Modeling \& Assessment, Volume 21, Issue 6, pp 819-833.

23. Moss RH, Edmonds JA, Hibbard KA, Manning MR, Rose SK et al (2010) The next generation of scenarios for climate change research and assessment. Nature 463:747-756

24. Van Vuuren DP, Edmonds J, Kainuma M, Riahi K, Thomson A, Hibbard K, Hurtt GC, Kram T, Krey V, Lamarque J-F, Matsui T, Meinshausen M, Nakicenovic N, Smith SJ, Rose SK (2011a) Representative concentration pathways: An overview. Climatic Change (this SI). doi:10.1007/s10584-011-0148-z

25. Fischer G (2009) How do climate change and bioenergy alter the long-term outlook for food, agriculture and resource availability? Expert Meeting on How to feed the World in 2050 (Rome, 24-26 June 2009). FAO. <Available at: ftp://ftp.fao.org/docrep/fao/012/ak972e/ak972e00.pdf>

26. Fischer G, van Velthuizen H, Shah M, Nachtergaele FO (2002) Global agro-ecological assessment for agriculture in the 21st century: Methodology and results. IIASA RR-02-02, IIASA. Laxenburg, Austria Fischer G, Shah M, Tubiello FN, van Velhuizen H (2005) Socio-economic and climate change impacts on agriculture: an integrated assessment, 1990-2080. Phil Trans Royal Soc B. doi:10.1098/rstb.2005.1744

27. Fischer G, Tubiello FN, van Velthuizen H, Wiberg DA (2007) Climate change impacts on irrigation water requirements: effects of mitigation. Technol Forecast Soc Chang 74(7):1083-1107

28. Fischer G, Hizsnyik E, Prieler S, Shah M, van Velthuizen H, (2009) Biofuels and food security. OFID/IIASA, Vienna/Laxenburg. <Available at: http://www.iiasa.ac.at/Research/LUC/luc07/Homepage-NewsHighlights/Biofuels\%20Report\%20Final.pdf, accessed in Mai 2010>

29. Fisher B, Nakicenovic N, Alfsen K, Corfee Morlot J, De la Chesnaye F, Hourcade J.-C, Jiang K, Kainuma M, La Rovere E, Matysek A, Rana A, Riahi K, Richels R, Rose S, van Vuuren DP,

30. Warren R, (2007) Chapter 3: Issues related to mitigation in the long-term context. In: Climate change 2007: Mitigation. Contribution of Working Group III to the Fourth Assessment Report of the Intergovernmental Panel on Climate Change. Cambridge University Press, Cambridge, United Kingdom and New York, NY, USA

31. Agriculture Organization of United Nations IPCC (2008) Towards new scenarios for analysis of emissions, climate change, impacts, and response strategies. IPCC Expert Meeting Report on New Scenarios, Noordwijkerhout, Intergovernmental Panel on Climate Change

32. Nakicenovic N, Swart R (eds) (2000) Special Report on Emissions Scenarios (SRES). Cambridge University Press, Cambridge.

33. Ting Z, Yixuan Wang, Bing Wang, Ping Feng.(2018), Understanding the Main Causes of Runoff Change by Hydrological Modeling: A Case Study in Luanhe River Basin, North China,water,1-17.

34. Ashwathi P. Anil , H. Ramesh, Analysis of climate trend and effect of land use land cover change on Harangi streamflow, South India: a case study,(2017), Sustain. Water Resour. Manag Springer.

35. Dagnenet Fenta Mekonnen1, Zheng Duan, Tom Rientjes, and Markus Disse, Analysis of combined and isolated effects of land-use and land-cover changes and climate change on the upper Blue Nile River basin's streamflow, Hydrol. Earth Syst. Sci., 22, 6187-6207, 2018.

36. Shepherd, B., Harper, D. and A. Millington. 1999. Modelling catchment-scale nutrient transport to watercourses in the U.K. Hydrobiologia, 395-396: 227-238. 